\title{
EL ESCULTOR PEDRO DE HEREDIA Y LA HERMANDAD DE LA SOLEDAD DE LA VILLA DE SAN JUAN DEL PUERTO
}

\author{
THE SCULPTOR PEDRO DE HEREDIA \\ AND THE BROTHERHOOD OF THE SOLEDAD \\ OF THE VILLA OF SAN JUAN DEL PUERTO
}

\author{
Francisco Manuel Delgado Aboza \\ Colegio Cristo Rey, Sevilla. España \\ fdelgado@cristoreysevilla.es
}

\begin{abstract}
En el presente artículo analizamos, para lo que incluimos nuevas aportaciones documentales, los trabajos efectuados por el escultor Pedro de Heredia para la hermandad de la Soledad de la localidad de San Juan del Puerto (Huelva). Esta labor, realizada en 1574 y no conservada en la actualidad, consistió en la ejecución de una imagen de Cristo Yacente y su sepulcro.

Palabras claves: Pedro de Heredia; escultor; hermandad; San Juan del Puerto; siglo XVI.
\end{abstract}

In this paper we analyze, for which include new documentary contributions, works carried out by the sculptor Pedro de Heredia for the Brotherhood of the Soledad of the villa of San Juan del Puerto (Huelva). This work, carried out in 1574 and not preserved nowadays, consisted in the execution of an image of Laying Christ in tomb.

Keywords: Pedro de Heredia; sculptor; brotherhood; San Juan del Puerto; $16^{\text {th }}$ century.

Entre los numerosos escultores que se asentaron y trabajaron en la bulliciosa Sevilla del siglo XVI encontramos al maestro Pedro de Heredia, de cuya trayectoria profesional hay que destacar su participación en la ampliación del monumental retablo mayor de la catedral hispalense. La labor escultórica de dicha etapa corrió a cargo de varios escultores, entre los que podemos encontrar, junto al propio Heredia, a dos notables maestros de la época como fueron Roque de 
Balduque y Juan Bautista Vázquez "el Viejo". Pese a que conocemos un buen número de obras contratadas por Heredia, fundamentalmente para Sevilla y su antiguo reino, desgraciadamente son muy pocas las que se conservan en la actualidad, tal como ha sucedido con las dos piezas protagonistas de este estudio, que pese a todo vienen a incrementar el catálogo de uno de los escultores más reconocidos de la Sevilla del siglo XVI.

Respecto a su aprendizaje, apuntamos la concisa anotación que realiza Fernando Araujo Gómez en 1885, quien al hablar de la labor de Pedro de Heredia en el retablo mayor de la catedral de Sevilla, afirma que trabajó "con notable inteligencia, digna de un discípulo de Guillén"2. Pese a las dudas que nos plantea esta aseveración, pensamos que dicho autor se refiere al conocido entallador Diego Guillén Ferrant; este maestro, de origen francés, llegó a Sevilla, procedente de Plasencia, en el mes de abril de 1533, dilatando su estancia hasta $1547^{3}$. Sin embargo, recientemente se ha documentado por el profesor Palomero Páramo que Pedro de Heredia fue hijo del afamado escultor Jorge Fernández, aunque como vemos adoptaría el apellido de su madre Constanza de Heredia, por lo que es lógico pensar que casi con total seguridad su aprendizaje se desarrollaría bajo las directrices de su padre ${ }^{4}$.

Junto a los trabajos que le fueron encargados durante su vida profesional, debemos destacar que durante años ocupó el puesto de veedor del gremio de escultores y entalladores, lo que sin duda repercutiría positivamente en el reconocimiento e influencia que Pedro de Heredia alcanzó en la Sevilla de su época. Como sabemos, los alcaldes, diputados y veedores, como representantes del gremio,

${ }^{1}$ MORÓN DE CASTRO, María Fernanda: “Análisis histórico estilístico", en El retablo mayor de la Catedral de Sevilla. Sevilla, 1981, pp. 161-165; HERNÁNDEZ DÍAZ, José: "Iconografía y arte", en El retablo mayor de la Catedral de Sevilla. Sevilla, 1981, p. 85; HERNÁNDEZ DÍAZ, José: "Retablos y esculturas", en La Catedral de Sevilla. Sevilla, 1991, pp. 240 y 252-253; y HERRERA GARCÍA, Francisco Javier: "Los orígenes de una afortunada creación artística. El retablo gótico en Sevilla", en El retablo sevillano. Desde sus orígenes a la actualidad. Sevilla, 2009, pp. 15-68.

2 ARAUJO GÓMEZ, Fernando: Historia de la escultura en España desde principios del siglo XVI hasta fines del XVIII y causas de su decadencia. Madrid, 1885, p. 112.

${ }^{3}$ PALOMERO PÁRAMO, Jesús Miguel: El retablo sevillano del Renacimiento. Análisis y evolución (1560-1629). Sevilla, 1983, pp. 115-118.

${ }^{4}$ PALOMERO PÁRAMO, Jesús Miguel: "El entallador Jorge Fernández. Las arras en Córdoba y el testamento en Sevilla", en Alma Ars: estudios de arte e historia en homenaje al Dr. Salvador Andrés Ordax. Valladolid, 2013, pp. 41-45; HERNÁNDEZ GONZÁLEZ, Salvador: La escultura en madera del Gótico final en Sevilla. La sillería del coro de la Catedral de Sevilla. Sevilla, 2014, pp. 211-267; y HERRERA GARCÍA, Francisco Javier: "Flandes-Canarias, a través de los talleres sevillanos. Un encargo escultórico a Sevilla a comienzos del XVI", en RODRÍGUEZ MORALES, Carlos (ed.): Homenaje a la profesora Constanza Negrín Delgado. La Laguna, 2014, pp. 315-345. 
tenían que vigilar que se respetaran las normas del oficio, mantener el buen trato entre los agremiados y cuidar de la escrupulosa diferenciación entre aprendices, oficiales y maestros. Para obtener el grado de maestro, el encargado de convocar el examen era siempre el alcalde, llevándose a cabo en presencia de dos diputados y dos veedores. Conocemos varios documentos que nos informan de la labor de Pedro de Heredia, siempre junto al escultor Gaspar del Águila, como veedor, llegando a examinar a algunos destacados artistas como Gerónimo Hernández, Miguel Adán (ambos en 1573), Andrés de Ocampo (1575) y Mateo Merodio (1577)

Por nuestra parte, aprovechamos este breve trabajo para dar a conocer una nueva escritura notarial en la que Pedro de Heredia y Gaspar del Águila actúan como veedores, en esta ocasión de Antonio de Cerecedo. Dicho protocolo se fecha el 15 de febrero de 1574, en la escribanía pública de Diego Gabriel, que se ubicaba en "la collacion de san salvador en el sementerio" (actual plaza del Salvador). En presencia del citado notario y de los testigos Juan Bautista Peñafiel y Bernardo Basurto, los dos escribanos de Sevilla, se presentaron los citados Pedro de Heredia y Gaspar del Águila "entalladores vezinos desta çiudad de Sevilla y dixeron que por quanto ellos son nonbrados por behedores del dicho ofiçio de entallador y de ymaginario por el Ilustrisimo cabildo e rregimiento de esta çiudad para este presente año", y que como tales veedores habían visto la llamada "validad suficiencia" de Antonio de Cerecedo ("Serecedo"), del que se dice que era entallador y vecino de la collación del Salvador.

Seguidamente, se explica que para poderle "examinar del dicho ofiçio es necesario que primero acabe un tabernaculo de talla del tamaño y de la forma y madera que me fuere señalado por los dichos vehedores"; igualmente, y ateniéndose a las ordenanzas del oficio, los veedores le concedían licencia y facultad para que desde la fecha de esta carta y en el plazo de tres meses pudiera usar el "ofiçio de entallador libremente sin yncurrir en ello en pena alguna y pidieron e suplicaron a qualesquier juezes e justiçias desta çiudad le dexen libremente usar el dicho ofiçio por el dicho tienpo en el qual le dan para que pueda acabar el tabernaculo de talla para que pueda examinarse del dicho ofiçio y lo pidieron por testimonio", lo que fue dado por el citado escribano público ${ }^{6}$. Poco tiempo después, según José Gestoso en 1576, talló los florones "para el artesonado del corredor á la entrada de los jardines del Alcázar"7; años más tarde lo vemos ocupando el puesto de veedor

${ }_{5}^{5}$ PALOMERO PÁRAMO, Jesús Miguel: El retablo sevillano del Renacimiento..., op. cit., pp. 54-55; y LÓPEZ MARTÍNEZ, Celestino: Desde Martínez Montañés hasta Pedro Roldán. Sevilla, 1932, pp. 9, 60-61, 74 y 87.

${ }^{6}$ AHPS (Archivo Histórico Provincial de Sevilla), sección Protocolos Notariales de Sevilla, leg. 13554, oficio 20, libro $1^{\circ}, 1574$, f. 565r-v.

${ }^{7}$ GESTOSO Y PÉREZ, José: Ensayo de un Diccionario de los artifices que florecieron en Sevilla desde el siglo XIII al XVIII inclusive. T. I. Sevilla, 1899, p. 178. 
y examinando, junto con Pedro de la Cueva, a Juan de Oviedo y de la Bandera (1586), Andrés de Castillejo y Juan Bautista (ambos en 1587) ${ }^{8}$.

Dentro de la amplia clientela que realizó encargos a Pedro de Heredia encontramos a distintas hermandades y cofradías del llamado antiguo reino de Sevilla. El 18 de noviembre de 1550 la cofradía de la Concepción de la iglesia de San Juan de la Palma de Sevilla, y en su nombre el prioste y platero Pedro Sánchez, le confiaba la ejecución de una imagen de un "Crucifijo al natural de madera hueco" -hoy desaparecido-, con una altura de ocho palmos $(1,67 \mathrm{~m})$; su coste se fija en veinte ducados ${ }^{9}$. Bastantes años más tarde, nos encontramos con el encargo de la hermandad de la Soledad de Arcos de la Frontera, que le encomienda la ejecución de un Cristo Resucitado y su sepulcro. La escritura notarial, fechada el 4 de julio de 1575, está ajustada por el escultor y Leonís de Ayllón Hidalgo, este último vecino de Arcos y hermano de la aludida cofradía. Pedro de Heredia se compromete a realizar "un xpo de rresurecion de madera con un sepulcro sobre que a de yr el xpo todo de buena madera de alamo blanco", presentando el Señor una altura de ocho cuartas o palmos. El plazo para acabar esta labor se establece a finales de octubre del mencionado año, fijándose un coste total, incluyendo la pintura y dorado, de cincuenta ducados ${ }^{10}$. Respecto a la talla del Resucitado, se viene identificando con la imagen que actualmente se ubica en el ático del retablo de San Pedro de la parroquia del mismo nombre de la citada localidad gaditana ${ }^{11}$; no obstante, otros autores rechazan esta hipótesis, alegando que es contemporánea al propio retablo, que se fecha a mediados del siglo XVI ${ }^{12}$.

Es en esta época, concretamente en 1574, cuando otra corporación dedicada al culto de Nuestra Señora de la Soledad, devoción que se extendió con fuerza por gran parte del reino de Sevilla desde el siglo XVI ${ }^{13}$, le encarga a Pedro de Heredia un nuevo trabajo. Nos referimos, ciertamente, a la hermandad de la Soledad de la villa onubense de San Juan del Puerto, corporación hoy extinguida que

${ }^{8}$ LÓPEZ MARTÍNEZ, Celestino: Desde Jerónimo Hernández hasta Martínez Montañés. Sevilla, 1929, pp. 38, 42 y 70.

9 MIRA CABALLOS, Esteban: "Una obra desconocida del escultor Pedro de Heredia para la Cofradía de la Concepción de San Juan de la Palma (1550)", Boletín de las Cofradias de Sevilla, 461, 1997, pp. 53-55.

${ }^{10}$ LÓPEZ MARTÍNEZ, Celestino: Desde Jerónimo Hernández..., op. cit., pp. 47-48.

11 PÉREZ REGORDÁN, Manuel: "Arcos de la Frontera, La Soledad", en Semana Santa en la Diócesis de Jerez. T. II. Sevilla, 1988, pp. 155-158; y FALCÓN MARQUÉZ, Teodoro: Iglesias de Santa María y San Pedro. Arcos de la Frontera. Sevilla, 1995, p. 28.

12 ALONSO DE LA SIERRA, Juan y otros: Guía artística de Cádiz y su provincia. T. II. Sevilla, 2005, pp. 319-320.

${ }^{13}$ CAÑIZARES JAPÓN, Ramón: "Las Hermandades de la Soledad en el antiguo Reino de Sevilla (I)", Boletín de las Cofradías de Sevilla, 609, 2009, pp. 869-875. Sobre este tema, resulta esencial el trabajo del mismo autor titulado Las Hermandades de la Soledad y Santo Entierro en el reino de Sevilla. Sevilla, 2014. 
tenía como titulares a una imagen de Cristo Yacente y a la Dolorosa bajo la referida advocación de la Soledad. Su fundación se viene fechando el 18 de julio de 1573, confirmándose su regla por el provisor del arzobispado de Sevilla, el licenciado Juan Rodríguez. Desde sus orígenes la corporación residió en la iglesia del convento de frailes carmelitas de Nuestra Señora de la Concepción, cenobio que había sido creado en 1529 y del que en la actualidad únicamente se conservan algunos restos ${ }^{14}$. Es en esta época inicial de la cofradía de la Soledad, cuando sus hermanos fundadores encargan a Pedro de Heredia la efigie de un Cristo Yacente y su sepulcro, que por desgracia no han llegado a la actualidad.

Efectivamente, el 19 de febrero de 1574 y ante el ya aludido Diego Gabriel, escribano público de Sevilla, el escultor Pedro de Heredia, residente en la collación de Santa María Magdalena -en la que vivió muchos años-, concertaba con Gaspar Quintero, vecino de San Juan del Puerto y prioste de la cofradía de Nuestra Señora de la Soledad de la mencionada localidad, la realización de un sepulcro de nueve palmos de largo $(1,88 \mathrm{~m})$ y con un Cristo "amortajado dentro". Entre las condiciones del trabajo, apuntamos que la urna se haría de "madera de borne"15, mientras que el Cristo Yacente tendría tallado en madera, aunque no se especifica ni su tipología ni su calidad, la cabeza, manos y pies; asimismo, se compromete a entregarlo "entallado y enbarnyçado y bestido con su tunyca"16.

Mucho más detallista se muestra la escritura respecto al sepulcro, que también se daría barnizado, además de presentar velos de "toca de seda" y "cinco angeles de pasta con las ynsignias de la pasion enbarnysados y dorados de la manera e forma que está en nuestra señora del carmen de esta ciudad de Sevilla"17. Sin duda, se refiere al sepulcro de la hermandad de la Soledad del convento casa grande del Carmen de Sevilla, actual Soledad de San Lorenzo, del que sabemos que también lucía cinco ángeles. Esta urna influiría en otras corporaciones de la época, e incluso en zonas alejadas como Tenerife. El 8 de abril de 1592 el pintor de imaginería Miguel Vallés, vecino de Sevilla en la collación del Salvador, concertó con Baltasar de Torres, procedente de la isla de Tenerife, la ejecución de "un sepulcro de madera de la hechura e pintura que el sepulcro que tiene la cofradia

${ }^{14}$ CARTES PÉREZ, Juan Bautista: "El convento del Carmen: Historia, devociones y patrimonio", en Cinco siglos de Historia de la villa de San Juan del Puerto (1468-1992). De la tradición marítima al proceso de industrialización. San Juan del Puerto, 1992, pp. 255271; y QUINTERO REBOLLO, Antonio Manuel: "445 años en la Semana Santa local 1573-2018", Fiestas de San Juan Bautista, San Juan del Puerto, 2018, pp. 56-62.

${ }^{15}$ Según el Diccionario de la lengua española de la RAE, se describe dicha madera de "poco elástica, quebradiza y difícil de labrar, de color blanco sucio y a veces parduzco, y que procede de árboles puntisecos y viejos".

16 AHPS, sección Protocolos Notariales de Sevilla, leg. 13554, oficio 20, libro $1^{\circ}, 1574$, ff. $333 \mathrm{v}-334 \mathrm{v}$.

17 Ibidem. 
de la soledad desta ciudad que esta en el Carmen"; igualmente, se habla de que se decoraría con tan solo un ángel de pasta ${ }^{18}$. Parece que esta urna se realizó para el llamado Cristo Difunto de Icod de los Vinos, actualmente en la iglesia de San Marcos de esta localidad tinerfeña ${ }^{19}$.

Siguiendo con la descripción de la urna de Pedro de Heredia para San Juan del Puerto, se puntualiza que tendría "quatro pilares a cada esquina unos quadrados con sus molduras una alta y otra baxa y asimismo a de lleuar el dicho sepulcro una moldura alta y otra baxa que se pueda quitar e poner y en el remate de las esquinas de la cobertura del sepulcro a de tener sus verdugos y en lo alto de todo ello una moldura que haga fin". Toda la labor contratada por el citado maestro se precisó en un coste de treinta y cinco ducados, abonándose en el momento de la firma de la escritura once ducados en reales al contado, declarándose por Heredia que ya estaban "en mi poder de que me doy por contento pagado y entregado a mi voluntad". De la misma forma, se fija como fecha de entrega el 28 de marzo de 1574 -tan solo un mes y medio de plazo para cumplir con el encargo-; en ese día se le daría otros nueve ducados y los quince restantes a finales del mes agosto de ese mismo año.

Como era habitual en este tipo de acuerdo, si en el plazo declarado no había entregado el Cristo Yacente y su sepulcro, el representante de la hermandad podía "plantar" al maestro sin más prueba que su juramento o declaración, pasando "vos el susodicho a mi costa lo podáis comprar en la parte e lugar que os pareciera". Hay que tener presente, que posiblemente el escaso tiempo que se acuerda para realizar el trabajo pudiera explicarse en el deseo de la hermandad de sacar el Viernes Santo de ese año la imagen del Señor en su sepulcro. Para acabar con dicho protocolo, vemos que aparece firmado por Pedro de Heredia, el escribano público Diego Gabriel y por los testigos, en nombre del prioste Gaspar Quintero que no sabía escribir, Bartolomé de Celada y Juan Bautista Peñafiel, ambos escribanos de Sevilla ${ }^{20}$.

Como ya hemos señalado, tanto el sepulcro como la efigie del Yacente no han llegado a nuestros días, desconociéndose los motivos de su desaparición, que quizás tendría que relacionarse con su mal estado de conservación o simplemente

${ }^{18}$ CAÑIZARES JAPÓN, Ramón: "El inventario de 1597 de la cofradía de la Soledad", Boletín de las Cofradías de Sevilla, 465, 1997, pp. 47-51; y LÓPEZ MARTÍNEZ, Celestino: Arquitectos, escultores y pintores vecinos de Sevilla. Sevilla, 1928, p. 202.

19 RODRÍGUEZ MORALES, Carlos: "Presencia e influencia de la escultura andaluza en Canarias", en La escultura del primer naturalismo en Andalucía e Hispanoamérica (1580-1625). Madrid, 2010, pp. 457-472; y AMADOR MARRERO, Pablo Francisco: Imaginería ligera novohispana en el arte español de los siglos XVI-XVII. T. I. Las Palmas de Gran Canaria, 2012, pp. 274-276.

20 AHPS, sección Protocolos Notariales de Sevilla, leg. 13554, oficio 20, libro $1^{\circ}, 1574$, ff. $333 \mathrm{v}-334 \mathrm{v}$. 
por cambios en los gustos estéticos. Fuera como fuera, lo cierto es que la hermandad de la Soledad en algún momento de su historia decidió sustituir la imagen del Cristo Yacente por otra, que felizmente se mantiene en la actualidad, aunque tras la extinción de la aludida corporación hoy es titular de la hermandad del Gran Poder de la misma localidad, con sede en la parroquia de San Juan Bautista. Es una notable talla anónima realizada en madera policromada, que se viene atribuyendo al círculo del escultor Pedro Roldán, fechándose hacia 1700 (Figura 1) ${ }^{21}$.

Fecha de recepción: 30 de octubre de 2018

Fecha de aceptación: 1 de julio de 2019

${ }^{21}$ CARRASCO TERRIZA, Manuel Jesús: "Patrimonio histórico-artístico de la iglesia parroquial de San Juan Bautista (SS. XVI-XX)", en Cinco siglos de Historia de la villa de San Juan del Puerto (1468-1992). De la tradición maritima al proceso de industrialización. San Juan del Puerto, 1992, pp. 353-395; GARCÍA-RÁEZ ROMERO, Rocío: "San Juan del Puerto. Hermandad de Nuestro Padre Jesús del Gran Poder y Nuestra Señora de los Dolores", en Huelva Cofrade. Historia de la Semana Santa de Huelva y su Provincia. T. III. Sevilla, 1997, pp. 477-484; CARRASCO TERRIZA, Manuel Jesús y GONZÁleZ GÓMEZ, Juan Miguel: Catálogo Monumental de la Provincia de Huelva. T. II. Huelva, 2009, p. 177; y QUINTERO REBOLLO, Antonio Manuel: "445 años en la Semana Santa...”, op. cit., pp. 56-62. 


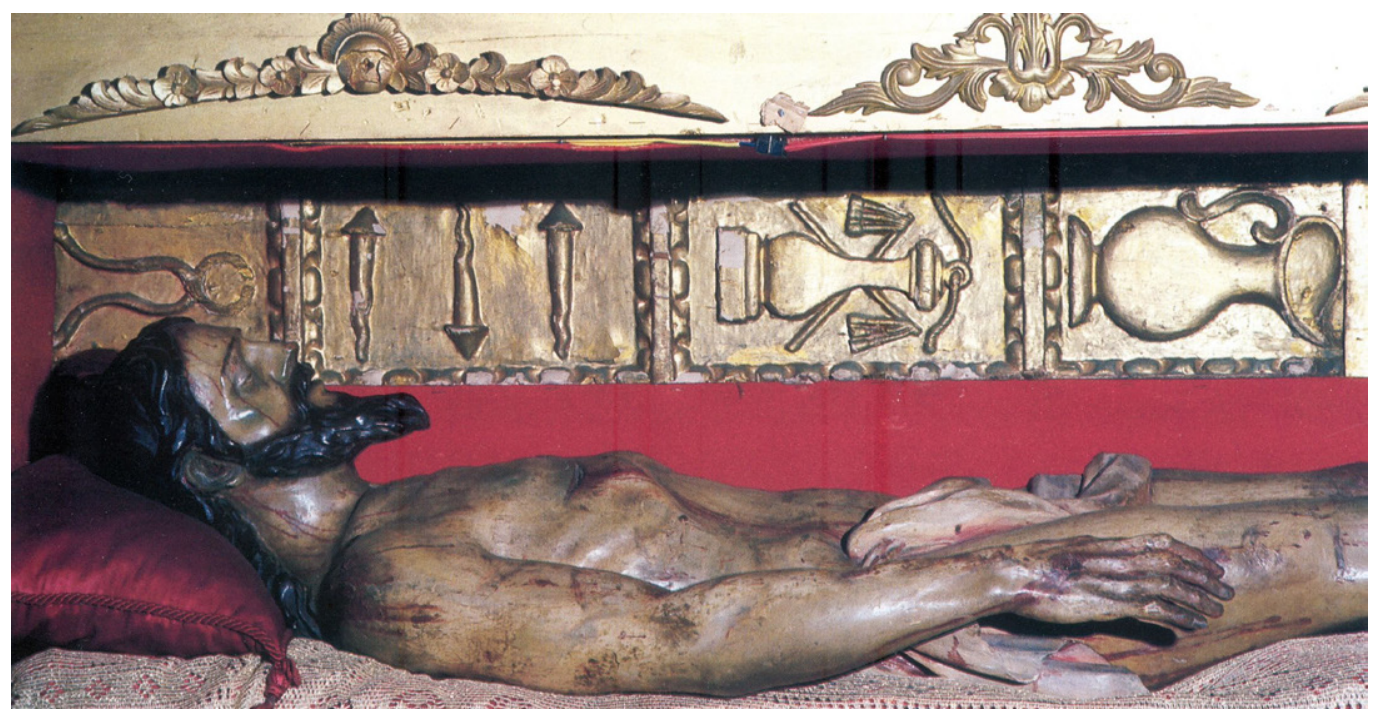

Figura 1. Atribuido al círculo de Pedro Roldán, Cristo Yacente, hacia 1700, parroquia de San Juan Bautista, San Juan del Puerto (Huelva). Foto: Juan Carlos Gallardo Ruiz. 